\title{
Optimal setting of DOC relay in distribution system in presence of D-FACTS
}

\author{
Lazhar Bougouff $^{1}$, Abdelaziz Chaghi ${ }^{2}$ \\ ${ }^{1}$ Department of Electrical Engineering, Faculty of Technology, University of El-Oued, El-Oued, Algeria \\ ${ }^{1,2}$ LSP-IE Research Laboratory, Department of Electrical Engineering, Faculty of Technology, University of Batna 2, \\ Algeria
}

\begin{tabular}{l} 
Article Info \\
\hline Article history: \\
Received Jan 16, 2021 \\
Revised Apr 13, 2021 \\
Accepted May 27, 2021 \\
\hline Keywords: \\
Breeder genetic algorithm \\
D-FACTS \\
Distribution system \\
DOC relays \\
TCSC
\end{tabular}

\begin{abstract}
The process of selecting optimal settings for directional over-current relays (DOC relays) is a selection of time dial setting (TDS) and IP (backup current), So that changes in the system of electrical power distribution. In this work, a breeder genetic algorithm (BGA) has been applied to optimal settings of DOC relays with multisystem D-FACTS devices. The simulation consists of two network operation scenarios, scenario without D-FACTS which consisting of coordination of DOC relays against three phase faults, and the second scenarios with multi TCSC. In general, had been verified on optimal settings of relays that the impacts of TCSC insertion in 33-bus distribution system on DOC relays.
\end{abstract}

This is an open access article under the CC BY-SA license.

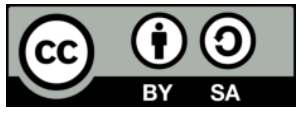

\section{Corresponding Author:}

Lazhar Bougouffa

Department of Electrical Engineering

University of El-Oued, El-Oued 39000, Algeria

Email: bougouffa-lazhar@univ-eloued.dz

\section{INTRODUCTION}

Power system shocks are reduced by providing insulation to the faulty area as quickly as possible, and this is the main goal of protecting the system. The protection is operating only after an abnormal or insupportable condition occurs, with sufficient signal to allow their operation. Relays operate to protect the primary zone and also operate correctly in response two conditions outside the primary protection zone. Therefore, backup protection is available for the area outside its main zone in these cases. The process of applying and adjusting the protective relays that exceed the primary relays so that they operate as quickly as possible in their area, but they do not work in a faster time in their backup area. This process is known as the relay coordination [1].

In order to study the negative or positive impact on the protection system in an electric network when a new compensation system is introduced into the distribution system, such as the distribution generation resource (DGR) [2] and distributed flexible AC transmission system (D-FACTS) and improving the new setting of the direction over-current relays after compensation. However, with the increasing integration of FACTS into the distribution network, the problem of coordinating protection relays becomes more difficult. In recent years, researchers have provided solutions and several methods to overcome the effect of a series controlled FACTS device on the optimal coordination of the over-current directional relay problem. A new idea is introduced in order to find out how affects of the series compensation degree on the setting of the over-current relays. For the same problem, the authors in [3] was present a solution to the new setting of DOC Relays and the problem of coordination using PSO technique. The aim of this optimization is 
to find optimal settings of TDS and Ip for relays, which reduces the operating time of the overall relays, other work [4] applied LP-Dual simplex algorithm to obtain the optimal TDS for a fixed IP. L. Bougouffa et al. [5], the authors study the effect of DG as well as a thyristor controlled series capacitor (TCSC) on the short circuit level in the distribution network.

The different optimization algorithms which were developed by researchers to investigate the impacts of FACTS on optimal settings and coordination of protection: Zahra M, Mostafa J and Mehdi Gh. [6] Modified adaptive particle swarm optimization (MAPSO), N. Mancer, B. Mahdad, K. Srairi et al. [7] Particle swarm optimization (PSO) algorithm based on time-varying acceleration coefficients (PSO-TVAC), E. Dehghanpour, H. K. Karegar, R. Kheirollahi et al. [8] Cuckoo-linear optimization algorithm, R. Benabid, M. Zellagui, A. Chaghi et al. [9] Differential evolution algorithm, Behzad A. M. A., Masoud E. T., Reza R. et al. [10] An adaptive cumulative sum based method.

In this work, breeder genetic algorithm (BGA) is proposed to select the optimal values of TDS for a fixed value of Ip and present a solution for the coordination problem of DOC relays in presence of D-FACTS devises. In this paper, the algorithm is applied to IEEE 33-bus system with multi-TCSC which is modeled and simulated to prove the efficiency of the proposed BGA. Moreover, the obtained results when using this algorithm are compared without and with TCSC.

\section{COORDINATION OF RELAYS PROBLEM}

Typically, the inverse time over-current relay consists of two elements, an instantaneous unit, and a time dependent unit. A time delay unit is used for the current, which is less than the instantaneous current setting, but exceeds the normal flow due to a fault. This unit operates when malfunction with a time delay. The two decisive factors are TDS and IP. The IP is the minimum current value for which the relay operates and the TDS defines the tripping time [11], [12]. In (1), the standard mathematical formula for modeling the operating time of relays according to IEC 60255 [13]:

$$
t=T D S \times \frac{\alpha}{\left(\frac{I_{f}}{C T_{r} \times I_{p}}\right)^{\beta}-1}
$$

Where, $\alpha$ and $\beta$ are constants. The values of these constants are given in [14], [15], $I_{F}$ is the current in abnormal operation at the primary of a current transformer, $\mathrm{CTr}$ is the current transformer ratio, DOC relays will operate rapid after sensing a high current in abnormal operation because the tripping time of relay is inversely proportional to the fault current [16].

\subsection{Objective function}

The TDS setting and the IP setting are two parameters that define the optimal coordination problem. Conventionally, in coordination studies, the objective function is formed as the sum of the operating times of all the primary relays [17]. In (2) represent the minimization of total operation time [6]:

$$
\min O F=\sum_{i=1}^{32} \operatorname{TDS} \times \frac{0.14}{\left(\frac{I_{f}}{C T_{r} \times I_{p}}\right)^{0.02}-1}
$$

Where OF is the objective function in sec, each relay would have 0.2 seconds as minimum operation time [18].

\subsection{Bonds on operation time of relays}

The aim of this study is to ensure that the over-current relays reduce faults in a very fast time, while maintaining coordination between the backup protection zone and the primary protection zone relays. Coordination is maintained when relays in primary protection zone operate faster than relays in backup protection zone with a difference time equal to or greater than the specified coordination interval. Three constraints are considered for the minimization problem [12]; the first constraint is CTI;

$$
T_{\text {back-up }}^{F I}-T_{\text {primary }}^{F I} \leq C T I
$$


The CTI should be the minimum margin between the pair of relays primary and backup [19, 20]. The margin of safety is set between $0.2 \mathrm{~s}$ and $0.5 \mathrm{~s}$ depending on the circuit breaker speed and the type of relay [21].

\subsection{Bonds on TDS and IP for each relay}

The main decision variable in the traditional approach to coordination of protection is the TDS. In (4) the TDS value for the relay $i$ is limited between the $T D S i^{\min }$ and the $T D S i^{\max }$ [22], [23].

$$
\begin{aligned}
& \operatorname{TDS}_{i}^{\min } \leq \operatorname{TDS}_{i} \leq \operatorname{TDS}_{i}^{\max } \\
& I_{P i}^{\min } \leq I_{P i} \leq I_{P i}^{\max }
\end{aligned}
$$

Where: TDSiE $[0.05,1.5]$ and $I_{P} \in[0.25: 0.25: 2.5]$.

\section{GOAL OF STUDY AND IMPACTS OF D-FACTS}

Directional over-current protection is used to protect the network, in abnormal operations in the distribution network. The presence of D-FACTS disturbs the performance of distribution network protection. However, the total fault current seen by the relays will be changed when there are D-FACTS. Based on the TCSC operation in inductive and capacitive modes, the Fault current might increase or decrease [24], [25]. The intensity of the current measured by the relays changed where TCSC is connected to the distribution network. Also, DOC relays are incapable to detect the fault current because TCSC operate as a fault courant limiter.

\section{BREEDER GENETIC ALGORITHM}

The BGA is a new evolutionary algorithm and similar to genetic algorithm (GA). However, BGA is based on artificial selection unlike GA which is based on natural selection.

\subsection{Selection}

The BGA uses truncation selection method. To perform this method, trial solutions are evaluated and ranked according to their fitness. The top T\% of the best individuals of the trial solutions is selected and goes through recombination and mutation to create the next generation. The rest of the individuals are discarded. The next generation of the best test solution, which is directly inserted in the next generation and the rest of the solutions is created by recombination and mutation. Recombination is similar to crossover in GAs. The process is repeated until an optimal solution is obtained or the maximum number of iterations has been reached. BGA is very versatile and easy to program [26].

\subsection{Recombination}

In volume recombination, a random vector $r$ equal in length to the parents' length is generated. The child $z i$ is produce by the expression [26], [27].

$$
z_{i}=r_{i} x_{i}+\left(1-r_{i}\right) y_{i}
$$

Where $\boldsymbol{x i}$ and $\boldsymbol{y} \boldsymbol{i}$ are two parents.

In line recombination, a single uniformly random number $\mathrm{r}$ is generated between 0 and 1 , and the child is obtained by the expression [27].

$$
z_{i}=r x_{i}+(1-r) y_{i}
$$

\subsection{Mutation}

One problem that has been of concern in GAs is premature convergence, where the search might converge on local optima rather than the desired global one. This has been minimized by preserving the diversity of the population by adding small injection of randomness or mutation [27]. This is achieved by adding a small vector of normally-distributed zero mean random numbers to each child before inserting it into the population. The standard deviation $r$ of the vector is very critical, as small $r$ might lead to premature convergence or big $\mathrm{r}$ might impair the search and reduce its ability to converge optimally. Therefore, it's better to use an adaptive approach were-by the rate is modified during the course of the search. The population is divided into two halves $\mathrm{X}$ and $\mathrm{Y}$. A mutation rate of $2 \mathrm{r}$ is applied to $\mathrm{X}$ while a mutation of $1 / 2 \mathrm{r}$ to 
$\mathrm{Y}$. The mutation $\mathrm{r}$ is adjusted depending on the population ( $\mathrm{X}$ or $\mathrm{Y}$ ) that is producing better and fitter solutions on average. If $\mathrm{X}$ individuals are fitter that the mutation rate, $\mathrm{r}$ is increased by $10 \%$, while if $\mathrm{Y}$ is fitter that the mutation rate, $\mathrm{r}$ is reduced by similar amount.

\section{DETERMINE THE RELAYS TDS}

The TDS adjusts the temporization before the relays operates whenever the current measured reaches the value equal to or greater than current setting of the relay [14]. In order to obtain appropriate protection and coordination, the proposed algorithm is illustrated in the Figure 1.

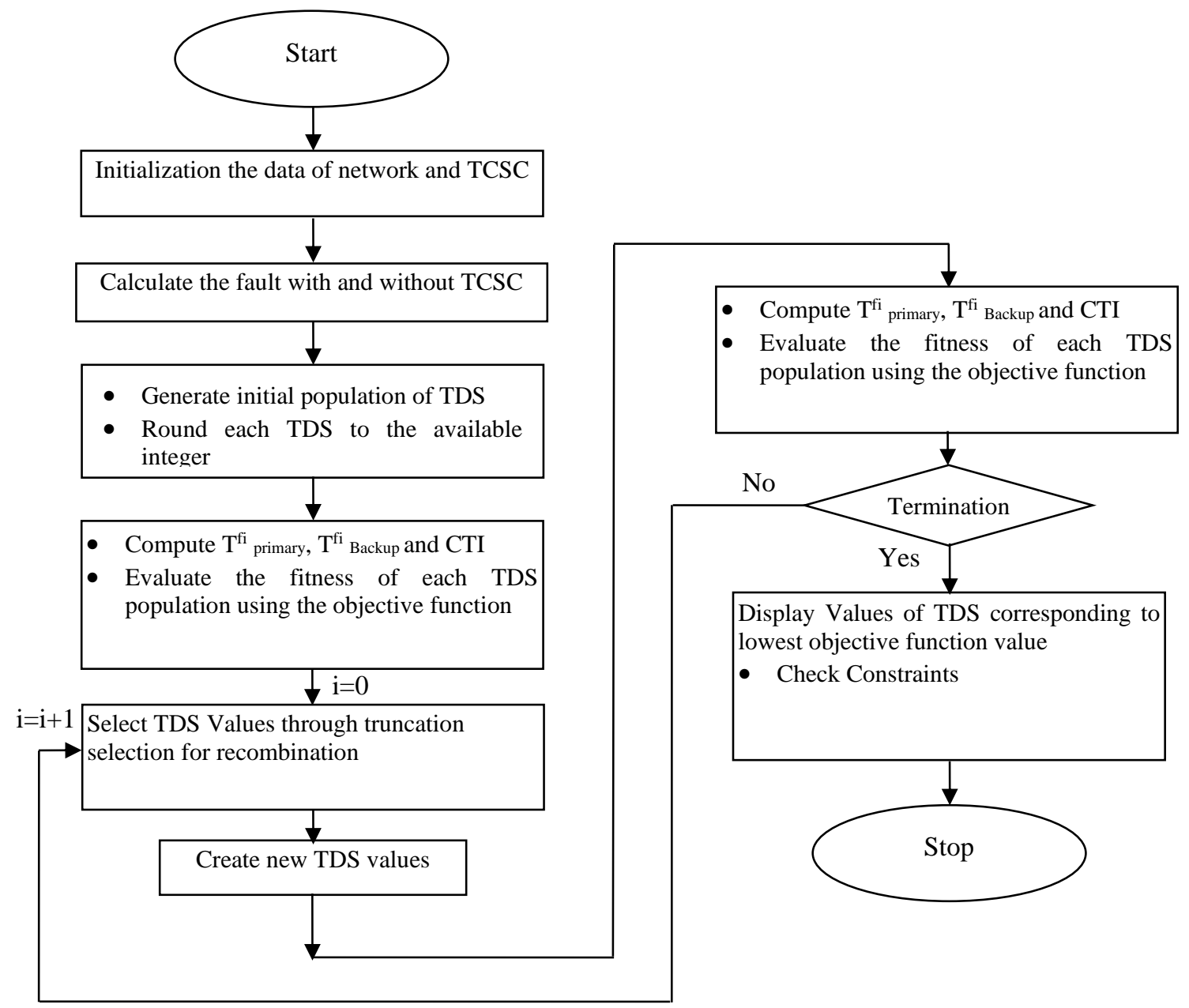

Figure 1. Flow chart for application of BGA for relay coordination with TCSC

\subsection{Power system model used for studies}

The network diagram used for studies is given in Figure 2 [3], [28]. BGA was applied on the $12.66 \mathrm{kV}, 100 \mathrm{MVA}$ distribution systems which consist of 33 buses, 32 directional over-current relays and four TCSC. Before the BGA is applied to the problem of coordination with TCSC, the following has to be done:

- Determine the pairs of relays for coordination

- Determine the fault current for each relay pair with and without TCSC.

- $\quad$ Determine the TDS for each relay for a fixed the pickup current to 1 . 


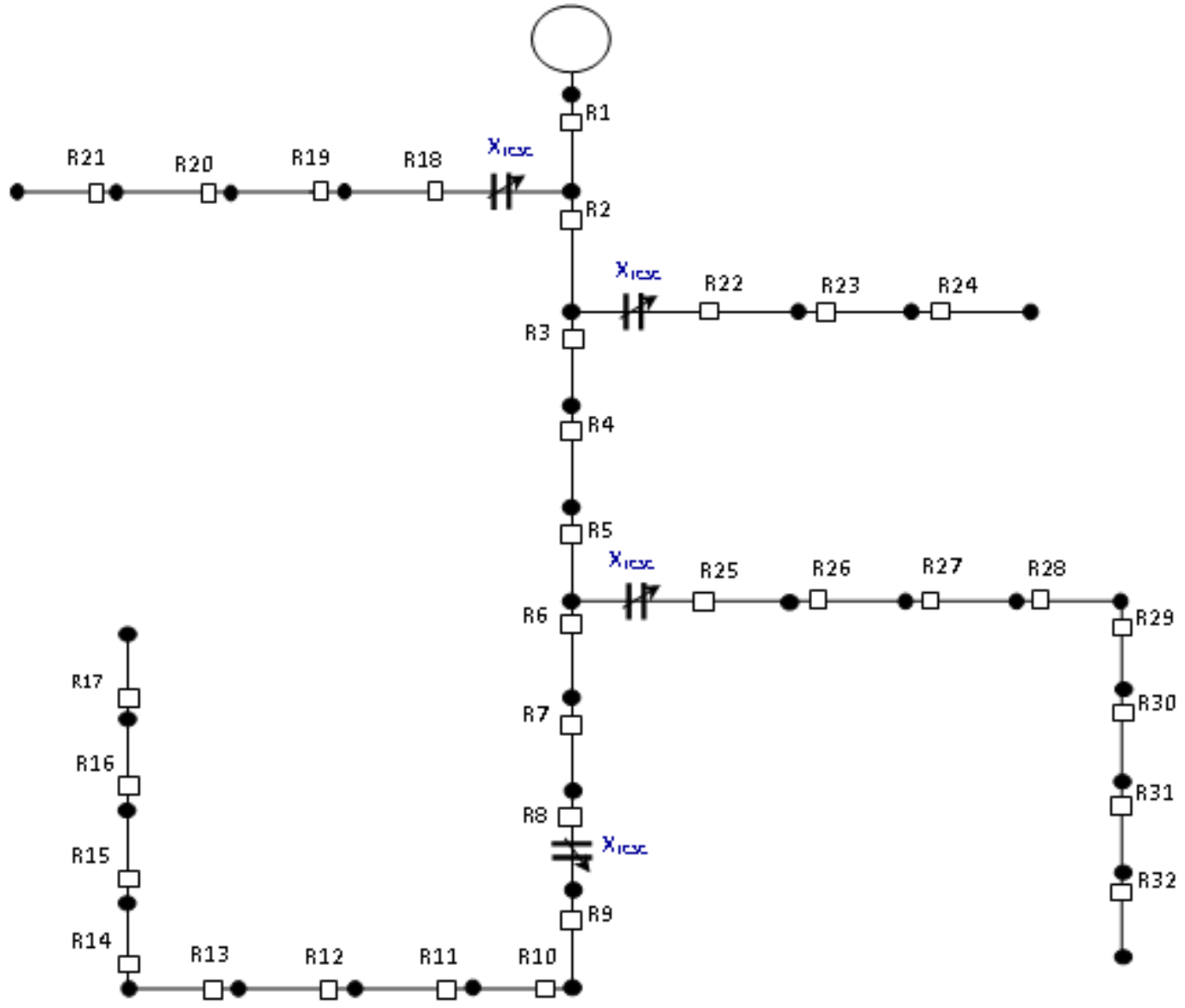

Figure 2. System diagram of power system model used for study

The validity of BGA is improved and tested on two scenarios. The first study consists of calculate the optimal settings of DOC relays without TCSC. Second case study consists of determine the optimal settings of DOC relays with the presence of multi-TCSC. The parameters of the TCSC are $\mathrm{L}=9.60 \mathrm{mH}$, $\mathrm{C}=212.2 \mu \mathrm{F}$. The rated value of TCSC is a function of the reactance where the TCSC is installed and expressed as:

$$
X_{\text {line }}=x_{i j}+x_{T C S C}
$$

Where:

$$
X_{T C S C}=K_{T C S C} \cdot X_{\text {line }}
$$

Where, $X_{\text {line }}$ is the overall line reactance with TCSC installation. $x_{i j}$ Is the reactance between bus-i and $\mathrm{j}$. $x_{T C S C}$ is the reactance of TCSC and $K_{T C S C}$ is the coefficient which represents the compensation level of TCSC. The working range of reactance of TCSC is fixed between -0.7 (capacitive) $\mathrm{X}_{\text {line }}$ and 0.2 (inductive) $\mathrm{X}_{\text {line }}[29]$. The TCSC is installed in the middle of the line; the three-phase fault equals the direct component is given by:

$$
I_{1}=\frac{V_{S}+V_{T C S C}}{Z_{i j-1}+\left(\frac{Z_{i j-1}}{2}\right)+X_{T C S C-1}+\left(\frac{Z_{i j-1}}{2}\right)}
$$

The opposite and homopolar components are equals to zero:

The current of three phases are given by: 


$$
\begin{aligned}
& I_{A}=\frac{\left(V_{S}+V_{T C S C}\right)}{Z_{i j-1}+\left(\frac{Z_{i j-1}}{2}\right)+X_{T C S C-1}+\left(\frac{Z_{i j-1}}{2}\right)} \\
& I_{B} \\
& =a^{2} \times \frac{\left(V_{S}+V_{T C S C}\right)}{Z_{i j-1}+\left(\frac{Z_{i j-1}}{2}\right)+X_{T C S C-1}+\left(\frac{Z_{i j-1}}{2}\right)} \\
& I_{C}=a \times \frac{\left(V_{S}+V_{T C S C}\right)}{Z_{i j-1}+\left(\frac{Z_{i j-1}}{2}\right)+X_{T C S C-1}+\left(\frac{Z_{i j-1}}{2}\right)}
\end{aligned}
$$

Where, $Z_{i j-1}$ is the direct component between bus-i and j. $V_{T C S C}$ is the voltage of TCSC

\section{RESULTS AND INTERPRETATIONS}

The results are provided to demonstrate the performance of the relays to isolate faults as quickly as possible for primary and back-up protection. The performance is evaluate by looking at the coordination time interval, operating time for primary zone fault and operating time for backup zone fault.

We have selected two angles for each mode (inductive and capacitive). Finally, the performance of settings for relay pairs is set in Table 1. The fitness value for the BGA algorithm drops rapidly in the beginning of the search from the initial value of 700 seconds to 78 seconds where it begins to settle to a

\begin{tabular}{|c|c|c|c|c|c|}
\hline \multicolumn{6}{|c|}{ With TCSC } \\
\hline \multirow{2}{*}{ relays } & \multirow{2}{*}{$\begin{array}{c}\text { Without } \\
\text { TCSC }\end{array}$} & \multicolumn{2}{|c|}{ inductive } & \multicolumn{2}{|c|}{ capacitive } \\
\hline & & $90^{\circ}$ & $135^{\circ}$ & $136^{\circ}$ & $180^{\circ}$ \\
\hline$T D S^{I}$ & 0.5200 & 0.5000 & 0.9700 & 0.1800 & 0.6300 \\
\hline$T D S^{2}$ & 1.2400 & 1.3400 & 1.6000 & 0.3400 & 0.5000 \\
\hline$T D S^{3}$ & 1.0600 & 0.0900 & 1.4400 & 1.1600 & 0.3800 \\
\hline$T D S^{4}$ & 0.9200 & 0.1400 & 1.1400 & 1.1800 & 0.5500 \\
\hline$T D S^{5}$ & 1.1300 & 0.8200 & 1.4600 & 0.4700 & 0.5200 \\
\hline$T D S^{6}$ & 1.1500 & 0.1000 & 1.0100 & 0.8200 & 0.3700 \\
\hline$T D S^{7}$ & 1.1200 & 0.5200 & 1.3800 & 1.0000 & 0.4700 \\
\hline$T D S^{8}$ & 1.0800 & 0.1400 & 1.2000 & 0.5800 & 0.1800 \\
\hline$T D S^{9}$ & 1.0800 & 1.1100 & 1.5000 & 0.8100 & 0.1700 \\
\hline$T D S^{10}$ & 1.0600 & 1.0900 & 1.0000 & 1.0100 & 0.5300 \\
\hline$T D S^{11}$ & 1.0300 & 0.1800 & 1.3100 & 1.0800 & 0.5400 \\
\hline$T D S^{12}$ & 1.2000 & 0.0900 & 1.1900 & 0.8600 & 0.1100 \\
\hline$T D S^{13}$ & 1.1100 & 0.1000 & 1.0700 & 0.5400 & 0.1900 \\
\hline$T D S^{14}$ & 1.0400 & 0.1400 & 0.9800 & 1.2000 & 0.2300 \\
\hline$T D S^{15}$ & 1.1300 & 0.3000 & 1.0800 & 0.4600 & 0.1200 \\
\hline$T D S^{16}$ & 1.1800 & 0.1900 & 1.0700 & 0.4100 & 0.3700 \\
\hline$T D S^{17}$ & 1.0500 & 0.1800 & 1.2800 & 0.8500 & 0.1100 \\
\hline$T D S^{18}$ & 1.1600 & 0.1700 & 1.4100 & 0.7300 & 0.3500 \\
\hline$T D S^{19}$ & 0.9700 & 0.6400 & 1.2500 & 1.1200 & 0.1200 \\
\hline$T D S^{20}$ & 1.2400 & 0.1900 & 1.2900 & 0.8400 & 0.1300 \\
\hline$T D S^{21}$ & 1.1800 & 0.2100 & 1.0400 & 0.3100 & 0.4700 \\
\hline$T D S^{22}$ & 1.1000 & 0.1000 & 1.1600 & 1.0100 & 0.2000 \\
\hline$T D S^{23}$ & 1.1400 & 0.3700 & 1.5700 & 0.4500 & 0.4000 \\
\hline$T D S^{24}$ & 1.1300 & 0.6800 & 1.3700 & 1.1200 & 0.3000 \\
\hline$T D S^{25}$ & 0.7200 & 0.1900 & 1.1500 & 0.5200 & 0.4700 \\
\hline$T D S^{26}$ & 1.0300 & 0.1900 & 1.1300 & 1.1400 & 0.3000 \\
\hline$T D S^{27}$ & 1.0900 & 0.1900 & 1.1000 & 0.7800 & 0.1100 \\
\hline$T D S^{28}$ & 1.1100 & 0.1700 & 1.3500 & 1.1400 & 0.4400 \\
\hline$T D S^{29}$ & 1.1300 & 1.0800 & 1.0200 & 1.0000 & 0.5000 \\
\hline$T D S^{30}$ & 1.1600 & 0.4200 & 1.1800 & 1.1800 & 0.1800 \\
\hline$T D S^{31}$ & 0.8900 & 0.3800 & 1.1700 & 0.1700 & 0.3500 \\
\hline$T D S^{32}$ & 1.2400 & 0.3300 & 1.1900 & 1.0700 & 0.5000 \\
\hline Obj.F & 75.9454 & 75.8682 & 76.8308 & 78.1341 & 77.3951 \\
\hline
\end{tabular}
fitness value in 10 iterations. It settles between 78 and 70 seconds for about 20 iterations. The algorithm maintains diversity and converges steadily until it reaches a fitness value that is within $7 \%$.

Table 1. Optimal setting of TDS using the BGA 
We see only the variations of the short-circuit current as a function of the reactance injected by the TCSC (ie substantially the operating mode of the TCSC in the system) is minimal in the inductive mode and maximum in the capacitive mode. According to the results obtained by the BGA method, it can be concluded that the TDS setting of all relays is less than 1.2 and greater than 0.05 , hence a satisfied standard. The main relay for the selected pair is Relay 8 and the backup relay is Relay 7. For this relay pair, three phase fault was simulated in bus-barre 9. This fault is in the zone of protection for relay 8 and in the backup zone of protection for Relay 7. For the proposed BGA, the TDS of relay 8 is 1.0800 seconds and Relay 7 is 1.1200 seconds without TCSC located at the branch between bus-barre 8 and 9. In the presence of the TCSC and its modes of operations, the results of the optimal settings of the pair of relays is clear in the Table 1 to guarding the coordination time interval of 0.3 seconds.

\section{CONCLUSION}

This study allowed us to design a procedure for optimizing the parameters of DOC relays in the presence of multiple TCSCs, based on BGA. This is performed to obtain the optimal setting values of TDS for each relay in IEEE 33-bus distribution system. The optimal TDS values achieved the required minimum operating time, which is $0.2 \mathrm{~s}$ for different TDS values. BGA show high capability to solve the coordination problem and provide better results compared to conventional methods.

We were able to achieve the objectives set out by obtaining efficient and robust relays. There are still many avenues to explore, but it seems to us a priority to continue a more in-depth study on the application of these techniques for simultaneous multi-objective optimization of D-FACTS and their locations by considering criteria such as minimization of response time, and the cost of installing D-FACTS.

\section{REFERENCES}

[1] J. Lewis Blackburn, Thomas J. Domin, "Protective relaying principles and applications," Third edition. Taylor and Francis group, New York, 2006.

[2] L. Bougouffa, A. Chaghi, "Effect of Renewable Energy Sources Integration on the Optimal Coordination of Directional Over-Current Relays in Distribution System," International Journal of Applied Power Engineering, vol. 9, no. 3, pp. 250-255, 2020, doi: 10.11591/ijape.v9.i3.pp250-255.

[3] L. Bougouffa, A. Chaghi, "Optimal Coordination of DOCR for Radial Distribution Systems in Presence of TCSC," International Journal of Power Electronics and Drive System, vol. 7, no. 2, pp. 311-321, 2016.

[4] L. Bougouffa, A. Chaghi, "Optimal Coordination Time Interval for DOCRs in Presence of D-FACTS," IEEE 5th International Congress on Information Science and Technology (CiSt), 2018, pp. 477-480, doi: 10.1109/CIST.2018.8596386.

[5] L. Bougouffa, A. Chaghi, "Impact of Distributed Generation and Series FACTS Compensator on Directional Overcurrent Protection Coordination," International Journal of Hybrid Information Technology, vol. 7, no. 4, pp. 299 308. 2014, doi: http://dx.doi.org/10.14257/ijhit.2014.7.4.25.

[6] Zahra M, Mostafa J, Mehdi Gh, "Optimal Coordination of Distance and Over-Current Relays in Series Compensated Systems Based On MAPSO," Energy Conversion and Management, vol. 56, pp. 140-151, 2012, doi: https://doi.org/10.1016/j.enconman.2011.11.024.

[7] N. Mancer, B. Mahdad, K. Srairi, M. Hamed, B. Hadji, "Optimal Coordination of Directional Overcurrent Relays Using PSO-TVAC," Energy Procedia, vol. 74, pp. 1239-1247, 2015, doi: https://doi.org/10.1016/j.egypro.2015.07.768.

[8] E. Dehghanpour, H. Kazemi Karegar, R. Kheirollahi, T. Soleymani, "Optimal Coordination of Directional Overcurrent Relays in Microgrids by Using Cuckoo-Linear Optimization Algorithm and Fault Current Limiter," in IEEE Transactions on Smart Grid, vol. 9, no. 2, pp. 1365-1375, 2018, doi: 10.1109/TSG.2016.2587725.

[9] R. Benabid, M. Zellagui, A. Chaghi, M. Boudour, "Optimal coordination of IDMT directional overcurrent relays in the presence of series compensation using Differential Evolution algorithm," 3rd International Conference on Systems and Control, 2013, pp. 1049-1054, doi: 10.1109/ICoSC.2013.6750984.

[10] Behzad A. M. A, Masoud E. T, Reza R, Behnam M-I, "An adaptive cumulative sum based method for unblocking distance relays in TCSC compensated transmission lines," International Journal of Electrical Power \& Energy Systems, vol. 131, p. 107095, 2021, doi: https://doi.org/10.1016/j.ijepes.2021.107095.

[11] A. Rathinam, D.Sattianadan, K. Vijayakumar, "Optimal Coordination of Directional Over-current Relays using Particle Swarm Optimization Technique," International Journal of Computer Applications, vol. 10. no. 2, pp. 4347. 2010.

[12] P. P. Bedekar, S. R. Bhide, "Optimum coordination of over-current relay timing using continuous genetic algorithm," Expert Systems with Applications, vol. 38, no. 9, pp. 11286-11292, 2011, doi: https://doi.org/10.1016/j.eswa.2011.02.177.

[13] Liang Ji, et al, "An Improved Inverse-Time Over-Current Protection Method for a Microgrid with Optimized Acceleration and Coordination,” Energies, vol. 13, pp. 1-17, 2020, doi: doi:10.3390/en13215726.

[14] D. Birla, R. P. Maheshwari, H. O. Gupta, "A new nonlinear directional overcurrent relay coordination technique, and banes and boons of near-end faults based approach," in IEEE Transactions on Power Delivery, vol. 21, no. 3, pp. 1176-1182, July 2006, doi: 10.1109/TPWRD.2005.861325. 
[15] Sharaf H. M, Zeineldin H. H, Ibrahim D. K, Essam El-Din A. E, "A proposed coordination strategy for meshed distribution systems with DG considering user-defined characteristics of directional in-verse time over-current relays," International Journal of Electrical Power \& Energy System, vol. 65, pp. 49-58, 2015, doi: https://doi.org/10.1016/j.ijepes.2014.09.028.

[16] A. S. Noghabi, H. R. Mashhadi, J. Sadeh, "Optimal Coordination of Directional Overcurrent Relays Considering Different Network Topologies Using Interval Linear Programming," in IEEE Transactions on Power Delivery, vol. 25, no. 3, pp. 1348-1354, July 2010, doi: 10.1109/TPWRD.2010.2041560.

[17] Azari Afshin, Akhbari, Mahdi, "Optimal coordination of direction- al overcurrent relays in distribution systems based on network splitting," International Transactions on Electrical Energy Systems, vol. 25, no. 10, pp. 23102324, 2014, doi: https://doi.org/10.1002/etep.1962.

[18] P. P. Bedekar, S. R. Bhide, "Optimum Coordination of Directional Overcurrent Relays Using the Hybrid GA-NLP Approach," in IEEE Transactions on Power Delivery, vol. 26, no. 1, pp. 109-119, 2011, doi: 10.1109/TPWRD.2010.2080289.

[19] M. Jazaeri, M. Gholamzadeh, "Considering the Effect of Series Capacitor in Optimal Coordination of Directional Over-currant Relays," Trends in Applied Sciences Research, vol. 7, no.6. pp 421-433. 2012, doi: 10.3923/tasr.2012.421.433.

[20] Tjahjono. A, "Adaptive modified firefly algorithm for optimal coordination of over-current relays," IET Generation Transmission \& Distribution, vol. 11, no. 10, pp. 2575-2585, 2017, doi: 10.1049/iet-gtd.2016.1563.

[21] IEC 60255-151, "Measuring Relays and Protection Equipment-Part 151: Functional Requirements for Over/under Current Protection," CiNii, 2009.

[22] M. Jazaeri, M. Gholamzadeh, "Considering the Effect of Series Capacitor in Optimal Coordination of Directional Over-currant Relays," Trends in Applied Sciences Research, vol. 7, no.6. pp 421-433. 2012, doi: 10.3923/tasr.2012.421.433.

[23] E. H. Gutierrez, A. Conde, M. Y. Shih, Erika Fernández, "Execution time enhancement of DOCR coordination algorithms for on-line application," Electric Power Systems Research, vol. 170 pp. 1-12, 2019, doi: https://doi.org/10.1016/j.epsr.2019.01.004.

[24] M. Nayeripour, M. Mahdi Mansouri, "Analyze of Real Switching Angle Limits in TCSC on Capacitor and Inductor Values and their Selection Factors," International Journal of Advanced Science and Technology, vol. 57, pp. 2536, 2013.

[25] P. K. Tiwari, Yog Raj Sood, "An Efficient Approach for Optimal Placement of TCSC in Double Auction Power Market," International Journal of Electronics and Electrical Engineering IJEEE, vol. 6, pp. 321-326, 2012.

[26] A. Phiri, K. A. Folly, "Application of Breeder GA to power system controller design," IEEE Swarm Intelligence Symposium, 2008, pp. 1-5, doi: 10.1109/SIS.2008.4668328.

[27] John Greene, "The basic idea behind the Breeder Genetic Algorithm," Department of Electrical Engineering, Technical report, University of Cape Town, 23 August 2005, Distributed Renewable Energy Sources.

[28] A. K. Sarma, K. M. Rafi, "Optimal Selection of Capacitors for Radial Distribution Systems Using Plant Growth Simulation Algorithm," International Journal of Advanced Science and Technology, vol. 2, no. 2, pp. 61-86, 2011.

[29] Nanda Kumar Easwaramoorthy, R. Dhanasekaran, "Solution of Optimal Power Flow Problem Incorporating Various FACTS Devices," International Journal of Computer Applications, vol. 55, no. 4, pp. 38-44, 2012.

\section{BIOGRAPHIES OF AUTHORS}

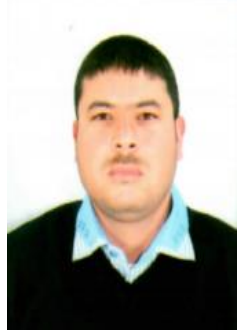

Dr. Lazhar Bougouffa was born in Batna, Algeria, 1986. He received his MASTER degree in Electrical Engineering from department of Electrical Engineering at University of Batna, Algeria, 2011, and received his Doctorate from Batna University, Algeria 2016. He is currently a lecturer of department of Electrical Engineering at Faculty of Technology El-Oued University, and member LSP-IE research laboratory at faculty of technology-University of Batna. His areas of interest include power system protection, power systems optimization, power quality and FACTS devices.

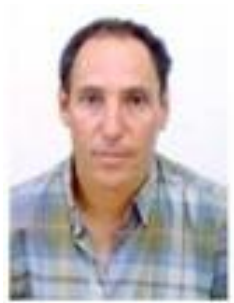

Prof. Abdelaziz Chaghi was born in Batna, Algeria, 1954. He received his BS degree from the University of Oran, Algeria 1980, and MS from the Manchester University, England 1984, and received his $\mathrm{PhD}$ from Batna University, Algeria 2004. He is currently a Professor at department of Faculty of Technology, Electrical Engineering and member LSP-IE research laboratory at faculty of technology-University of Batna. His areas of interest include power systems optimization, power system protection, renewable energy sources, harmonic, power quality and FACTS devices. 